\title{
A Study on the Implementation Distortion and Regression of the Kindergarten "De-primary" Policy
}

\author{
Jiao Zeng \\ Guangdong University of Foreign Studies South China Business College \\ Guangzhou, China 510545
}

\author{
Xiujun Wang \\ Guangdong University of Foreign Studies South China \\ Business College \\ Guangzhou, China 510545
}

\author{
Lan Wen \\ Guangdong University of Foreign Studies South China \\ Business College \\ Guangzhou, China 510545
}

\begin{abstract}
The implementation of the "de-primary" policy in kindergartens is conducive to the kindergartens arranging the content and forms of education according to the rules and cognitive characteristics of children's physical and mental development, and to maintaining children's learning interests and physical and mental health. However, at present, the implementation distortion of the "de-primary" policy in kindergartens has become a great obstacle for children to enjoy kindergarten life. Unbalanced educational resources, shortage of high-quality education resources, conflicts of interest between policy stakeholders, and lack of regulatory mechanisms are the main reasons for the "de-primary" phenomenon of kindergartens. To truly realize the policy goal of "de-primary" kindergartens, it is necessary to improve policy understanding, conform educational concepts, increase investment in education, balance educational resources, strengthen supervision of primary schools, and cut off the chain of interests. These will contribute to the effective implementation of this policy.
\end{abstract}

Keywords—kindergarten; de-primary; policy implementation; distortion

\section{INTRODUCTION}

There is a serious "de-primary" tendency of some kindergartens to violate the laws and cognitive characteristics of children's physical and mental development, teaching elementary content and strengthening knowledge and skills training, which should be conducted in primary school. In view of this problem, the Ministry of Education recently issued the "Notice about Special Governance Work on the "Primary tendency" of Kindergartens". In fact, as for the "primary tendency" of kindergartens, the Ministry of Education issued the "Notice on Regulating the Preschool Education and Preventing the 'Primary tendency' " in 2011, which strictly forbids kindergartens teaching primary content in advance. Kindergartens shall not carry out various advance learning and intensive training activities in the name of holding interest classes, specialty training class and experimental classes, and shall not set homework for young children. In 2012, the Ministry of Education issued the
"Guidelines for the Learning and Development of Children Aged 3-6", proposing that kindergartens shall prevent and overcome the "primary tendency". Although the education authorities have issued a series of stipulations to forbid the "de-primary" tendency of kindergartens, that the kindergarten is not "primary school", this phenomenon has not been curbed, but like a virus to spread to kindergartens at all levels, which has ruined the entire preschool education atmosphere. Why is it so difficult to implement the "deprimary" policy in kindergartens? How to solve the problem of kindergarten's implementation distortion of the "deprimary" policy? This article will discuss these issues.

\section{The MANifESTATIONS OF THE Distortion OF "DE- PRIMARY" POLICY}

G. Ellison, a well-known American administrative scholar, pointed out: "In the process of achieving policy objectives, the functions determined by the program only accounts for $10 \%$, while the remaining $90 \%$ depends on effective implementation." "1 However, in reality, the implementation of the "de-primary" policies is distorted in many ways.

\section{A. Symbolic Execution of Policies}

The "de-primary" policies are executed symbolically, which means the execution falls to superficial level, that is, kindergartens just say one thing and do another. It specifically means that the policy implementing subjects, kindergartens propagandize the policies vigorously but actually don't take any specific measures, causing the failure of these policies. The education department has enacted a series of regulations to forbid kindergartens teach elementary school content in advance. However, in the face of interests and realistic pressure, some kindergartens are learning the spirit of the notice issued by the educational authorities while continuing to making children learn mental arithmetic and English and recite massively [1]. Some kindergartens cancel the English, arithmetic and other learning when they are inspected. They collect relevant books and students' 
homework, and even ask parents to cooperate, not to let it out. And parents are happy to strictly guard the "secret" for the kindergarten. After the inspection is over, the kindergarten and parents will once again have pleasant cooperation, that is, the kindergarten will continue to teach students double-digit addition and subtraction while parents will continue to play the role to pull children to grow as tiger parents. Or some kindergartens change the name of the courses and continue to teach elementary school in the name of interest classes, specialty training classes, and experimental classes. In 2017, the China Academy of Educational Sciences conducted a survey to 442 kindergartens in western China, showing that about twothirds of kindergartens have a certain degree of "primary" tendency. Many kindergartens have Pinyin, English, and Literacy courses; others even offer courses in computers and abacus mental calculation. [2]

It can be seen that on the one hand, the education department keeps issuing documents, public opinion vigorously promotes the "de-primary" kindergarten, and on the other hand, kindergartens and parents play are playing the cat-and-mouse game with local governments and education departments. There primary teaching forms and contents of all kinds are still being given to children.

\section{B. Selective Implementation of Policies}

The selective implementation of the policy means that in the process of implementing the education policy, the subject of the policy make arbitrary choice of the content and spirit of a complete education policy based on their own interest. They carry out the part that is favorable to them; but they just intentionally misinterpret and discard the part that is not. [3] The Ministry of Education's documents require that "the teaching of elementary school curriculum in kindergarten is strictly prohibited, including Chinese Pinyin, Literacy, Computation, English, etc.; the primary school education methods, including mechanical memorization, transcription, calculation, etc. to intensify the training of knowledge and skills" should be corrected. When implementing the policy, some kindergartens found it not a bad thing to abandon the English course, because it is difficult to recruit good preschool English teachers and expensive to employ foreign teachers. Therefore, they will preach the policy to parents: English courses are not provided because they are not allowed by the policy. Some kindergartens did stop Chinese language content such as pinyin and literacy. But when they found that parents have been keen on the curriculum of Chinese studies in recent years, they just catered to parents' likes by making children recite a lot of classic contents, such as "Three-Character Scripture", "Disciple Gauge", "Thousand-character classic", and even the contents of the "Four Books and Five Classics." Some kindergartens stopped teaching the addition and subtraction of mathematics of primary curriculum, but began to open the "abacus mental calculation" courses to satisfy parents. From a certain point of view, hitting edge ball of policy to "diversify the curriculum" like this is selective implementation of policies to meet its own needs.

\section{Rigid Implementation of Policies}

The rigid implementation of policies means that when implementing educational policies, the executive subjects of the educational policies adopt a negative attitude, without exerting subjective initiative, seeking effective ways and measures for the implementation of educational policies, and creating the environment, conditions, timing required for the implementation of these policies. Their mechanical obedience for the policy seems to be active implementation, but actually it has a very negative effect on the realization of the educational policy objectives. [3] Some kindergartens, especially some kindergartens with poor conditions or in backward areas, interpret the "de-primary" policy of kindergartens as that it is not necessary to let children read and learn, they just need to look after and play games with children. With already weak teaching staff, these kindergartens have become kindergartens that just look after children without teaching and culturing them after they began to implement the policy rigidly. In the inspection, if the kindergartens are only evaluated by whether it has provided primary school curriculum or take primary teaching methods for children according to the indicators, such kindergartens are certainly accord with the evaluation criteria Therefore, this kind of kindergartens that rigidly implement policies worth special vigilance.

\section{Pinned Implementation of Policies}

The pinned implementation of the policy means that in the process of implementation of the education policy, the relevant supporting policies are insufficiently or pinned by other policies. In this case the implementation of the education policy is affected and its objectives are deviated. [3] The "de-primary" tendency is seemingly the kindergartens' fault. But in fact, parents, social training institutions and primary schools are also to blame. The reporter interviewed Ms. Xu Jing from Shenyang City, Liaoning Province whose daughter was 5 and half years old in kindergarten. According to her, the kindergarten where her daughter is attending did not teach the contents of primary school. Even the original foreign teacher classes were cancelled. At present, only arithmetic within 10 is taught in the middle class; even pinyin is not on the list. However, Xu Jing feels a little pity. She hopes that kindergartens can teach first-year courses in advance, because other kindergartens continue to teach them, so if her child does not learn she will fall behind her peers. [4] This is a typical anxious parent who does not want to let their children lose on the starting line. When searching online for entrance exam questions of some key elementary school, it can be seen that the difficulty of this test is not a child's ability to come over. Only children who have learned first-grade can complete the test. After kindergartens are banned from teaching elementary school courses, huge demand contradictions brought by it provide a broad market for social training institutions. Therefore, realistic problems like primary school entrance examinations, the rapid progress of primary teaching, the anxiety of parents, and the social institutions "grabbing" middle-class students of kindergartens are all pinning the implementation of the "de-primary" policy. 


\section{ANALYSIS OF THE REASONS FOR THE DISTORTION OF THE "DE-PRIMARY KINDERGARTEN" POLICY}

\section{A. Unbalanced Educational Resources and Shortage of High-quality Education Resources}

Insufficient financial input that making private kindergartens obey the parents for survival, imbalanced distribution of educational resources that causes the overwhelming attraction of high-quality primary schools are important reason for the distortion of the kindergarten "deprimary" policy.

First of all, the financial input in pre-school education in China is in severe shortage. According to the 2017 China's Kindergarten Industry Research Report, China's fiscal education expenditure in 2016 accounted for $4.22 \%$ of GDP, lower than the world average of $7 \%$. Preschool education, which does not belong to the compulsory education stage, accounts for only $7.2 \%$ of the total education budget of the state, accounting for $0.3 \%$ of the total GDP, which is 280.2 billion Yuan. The proportion of public kindergartens is low. According to the 2016 National Statistical Report on Education Development, private kindergartens accounted for $64.3 \%$ of the national kindergartens, and children in the private kindergartens accounted for $55 \%$ of all children in kindergarten. In the context of limited funding, private kindergartens receive very limited financial resources so tuition fees are their main source of funding. This causes kindergartens, in order to survive, to try to meet parents' needs when they asked for primary courses for their children. If kindergartens do otherwise, they will suffer from loss of students to other kindergartens or social training institutions.

Secondly, not only does the current quality of primary education in China vary, but the high-quality educational resources are also in great shortage and concentrated on big cities, which becomes a competitive target for capable families. Parents try to do everything to send their children to high-quality schools to receive education, in order to help them take the lead in their starting point of education. Quality primary schools face a large number of pursuers and limited resources, so they have to choose the best. As a result, a variety of primary school entrance exams with increasing difficulty have emerged, which in turn has led parents to ask kindergartens to teach their children primary school courses so that their children can achieve excellent results in their entrance examination. The premise of the disappearance of the primary school entrance examination is that the quality of education in all primary schools is basically the same. In this case parents can just bring their children to a nearby school instead of choose one specifically. However, the reality is that there is a resource imbalance in the current compulsory education stage, and there is a huge gap between different schools, which provides an unfavorable implementation environment for the kindergarten to eliminate the "primary" tendency.

\section{B. Conflict of Interest Between Policy Stakeholders}

"The implementation of any education policy will inevitably involve the redistribution of interests among different educational groups. Each group will certainly interpret and implement the policy from its own best interest." [5]Therefore, how the policy stakeholders' interest get satisfied determines how much they support the policy. So the conflict of interest among policy stakeholders often becomes an important cause of policy distortion.

The first is the conflict of interest between policy makers and policy performers. Policies like the "de-primary" Kindergarten, threshold teaching in primary school as well as prohibition of primary school entrance examination aim to have children nursed and taught scientifically by following children's physical and mental development rules and cognitive characteristics of in the kindergarten stage. However, kindergartens as policy implementers, the dual roles of "social people" and "economic people" forcing them to pay more attention to the role of "economic people" in the competition for survival, accordingly passively responded to the "de-primary" policy of kindergartens. The ban of the primary school entrance examination will cause the quality primary schools to lose more benefits from their selective entrance. In order to protect their own interests, the schools will also try to adopt various methods to conduct entrance examinations for students and select quality students to ensure their high prestige in the education market to attract more students. At the same time, some local governments also regard quality schools as a direct reflection of their "performance" of local work. Therefore, they just turn a blind eye to the primary school entrance examination. This will enable the school to obtain high-quality students to improve the rate of enrollment to middle school, thus create an education brand. This is contrary to the original intention of the policy, and will cause the relevant policies to fall to a failure.

The second is the conflict of interest between policy makers and policy objects. The objects of policy implementation are children and parents. Parents are more concerned about the future development of their children. So as long as the quality primary school entrance exams exist, parents must let their children learn the primary school curriculum in advance to achieve good results in the examination. . In addition, the teaching of many primary schools is not really for beginners for the teaching progress is very fast. In order to prevent their children from falling behind in the initial stage, parents also attach great importance to teaching primary courses in advance.

\section{The Policies Lack an Effective Monitoring Mechanism}

1) The supervision is costly: In the implementation of policies such as "de-primary" kindergarten, "primary school threshold teaching", and "ban of training institutions from holding preschool classes", the supervision require a large quantity of human, material and financial resources. The more objects to be supervised is, the more accurate the supervision is and it is more costly. The "de-primary" policy of kindergartens is a comprehensive macro-policy policy involving all public and private, large and small kindergartens in the country, as well as primary school and social training institutions. It will be very expensive for policy makers to supervise specific situation of an 
organization. Therefore, it is inevitable to simplify the process of supervision.

2) The supervision method is unitary: The kindergartens' implementation of the "de-primary" policy often takes the form of filling out data forms, writing selfassessment reports and work reports, which lacks supervision mechanism for society and related stakeholders. The inspection of the superiors is done under the form filling and the on-site arrangement of the policy implementer. What is shown is what the officials of the education administrative department want to see, causing to various falsehoods such as false reports, false reports, and false reports.

3) There is a lack of accountability system: There is a lack of necessary reward and punishment measures towards the results of the implementation of the "de-primary" policy in kindergartens. So far, only rare are severely punished for the poor implementation of the "de-primary" policy. There are very few, if any, rectifications are required, even fewer stricter penalties, and no corresponding law or regulation. On the contrary, some public kindergartens are strictly backward in the first grade of primary school because of the strict implementation of "de-primary" policy. Parents are very dissatisfied and consider that the quality of the kindergarten is poor.

\section{The Ultimate Path of the Kindergarten "DE- PRIMARY" POLICY}

\section{A. Improving Policy Understanding and Changing Educational Concepts}

To realize the "de-primary" goal of kindergartens across the country, policy awareness must be firstly promoted. The concepts of national and local education administrative departments at all levels along with the kindergartens and parents should be unified to realize the significance of the "de-primary" kindergarten teaching. And the kindergartens should arrange for teaching content and forms according to the physical and mental development rules of children. Second, the government and kindergartens should strengthen educational propaganda, establish right public opinion orientation and correct people's concept of "talent". And families, schools and the society should set up correct and diversified talent training concepts, and abandon the misconception "don't lose at the starting line" so that a good atmosphere for preschool education can be created.

\section{B. Increasing Educational Input and Balancing \\ Educational Resources}

The balance of educational resources is an important guarantee for the effective implementation of the "deprimary" policy in kindergartens. On the one hand, there are inter-school differences between primary schools. If we ignore the current huge inter-school differences and strictly implement the test-free admission policy to improve the enrollment rate, the burdens and pressures of primary school entrance will be even larger. To truly achieve primary school admission without interviews, we must try to narrow the gap of the conditions among primary schools to make parents feel at ease to send their children to any primary school. Therefore, the key to the elimination of the primary school entrance examination is the balanced development of all schools. There will not be competitive entrance examination if there is no need to choose a school.

On the other hand, there is a difference in financial support between public and private kindergartens. The funds of most private kindergartens are mainly from tuition fee income. The result of complete marketization is that kindergartens have to try their best to meet market demand. When they are required to teach elementary school content in advance by parents, the kindergartens cannot refuse, so as to avoid losing students and affecting their reputation. Therefore, it is necessary to vigorously develop inclusive kindergartens of high quality, in order to make parents believe in the quality of kindergartens, and in turn to guide parents' views on education and talents.

\section{Strengthening the Supervision of Primary Schools and Cutting off the Benefit Chain}

If there is no primary school entrance examination, all the first grade of primary school will start from the threshold teaching. In this way will there be no pressure for the entrance examination, thus no concern for the backwardness from the start of primary schools so that parents will not require the kindergartens to teach primary school content. Actually most parents hope that their child will have a happy childhood and the kindergarten will arrange the teaching content and teaching methods according to the rules of children's physical and mental development.

Therefore, in the process of supervision, we must not only focus on the behavior of kindergartens, but also make it a priority to supervise the primary schools, which can reduce the motivation of kindergartens and parents to make children learn primary school contents. In addition, we must strictly supervise social training institutions whose training content and form are most insidious. Some unscrupulous merchants even make a big hue and cry about the benefits of receiving primary school courses for children to receive primary school courses for their own benefit, in the name of dispelling melancholy for parents, though. But the truth is that their teaching methods often violate the laws of children's physical and mental development. And since the supervision of social training institutions involves multiple departments, it is most likely to become a supervision vacuum.

\section{CONCLUSION}

Kindergarten education and primary education, both as important components of basic education, are closely related but distinctly different stages of education. Kindergarten education has its own unique educational principles, content, methods and evaluating means. It is not reasonable to preliminarily teach the content of primary school curriculum in the organizational form and teaching methods of primary schools. Kindergartens must eliminate the "primary" 
tendency, but should also avoid mechanical implementation of the national policy. It is undesirable not to dare even to teach the linking part between kindergarten and primary school, which is overcompensation, bringing "children's happy learning" and "knowledge education" in conflict, Kindergarten education and primary school education are continuous. The characteristics of children's physical and mental development cannot be same as the two distinct stages of education divided by people. There is a transitional period between the two, similar to the "changeover" time space zone in the relay race. Therefore, the linking part between kindergarten and primary education is related to the lifelong development of young children. Therefore it is necessary to look at the "de-primary" kindergartens and the linking job between preschool school and primary school education from the perspective of lifelong education.

\section{REFERENCES}

[1] Wang Fusheng. Policy Research [M]. Chengdu, Sichuan People's Publishing House, 191:167.

[2] CCTV. Kindergarten should be like a kindergarten! How can childhood be returned to children? [EB/OL]. https://mp.weixin.qq.com/s/sudfd0q6IV542713jKlsLA.2018-08-04.

[3] Yi Hualiang. Distortion of Education Policy: Concept, Characteristics, and Main Performance [J]. Modern Education Management. 2009(1).

[4] Yang Shanshan. Kindergarten "Primary School": With such over-all situation, parents are helpless [N]. Legal Daily. 2018-08-01.

[5] Yuan Zhenguo. Educational Policy Science [M]. Nanjing: Jiangsu Education Press, 2001: 332. 